\title{
KINESIOPHOBIA IN SKIERS WITH KNEE INJURIES
}

\author{
HELENA JEDVAJ', DALIBOR KISELJAK², OLIVERA PETRAK² \\ ${ }^{1}$ University of Rijeka, Faculty of Health Studies, Rijeka, Croatia \\ ${ }^{2}$ University of Applied Health Sciences, Zagreb, Croatia
}

\author{
Mailing address: Dalibor Kiseljak, University of Applied Health Sciences, 38 Mlinarska Cesta Street, 10000 Zagreb, \\ Croatia; e-mail: dalibor.kiseljak@gmail.com
}

\begin{abstract}
Introduction. Alpine skiing is one of the most dangerous winter sports that entails a high number of injuries, most commonly affecting the knee. Kinesiophobia is a condition in which an individual experiences fear of physical movement and activity as a result of feeling susceptible to injuries or recurrent injuries. The objective was to examine the level of kinesiophobia in skiers who have sustained knee injuries. Material and methods. The sample consisted of 22 female and 11 male professional skiers, with the average age of $24 \pm 7.391$ years. For the purpose of the assessment, the Tampa scale for kinesiophobia (TSK) was employed. Results. The number of knee injuries in skiers totals at least 1 and 11 at most, on average 2.45, most commonly involving the anterior cruciate ligament and meniscus. There were no significant differences between the left and the right knee or bilateral injuries. The average score in the TSK totals 36 points, which is close to the critical threshold of 37 points. 36\% of the participants possess a high level of kinesiophobia. With respect to the general level of kinesiophobia, no significant differences were found in relation to gender, with regard to the number of surgeries or whether one or both knees were affected by injuries. Older skiers have also been found to have significantly lower fear of recurrent injuries. Conclusions. The number of knee injuries in skiing is high and aggravating, in such a way that almost one third of skiers that have sustained knee injuries experience a critical level of kinesiophobia, and that requires intervention. During rehabilitation, psychological support should also be provided to athletes in order to prevent or reduce kinesiophobia and thus prevent recurrent or new injuries.
\end{abstract}

Key words: alpine skiing, fear of movement, prevention

\section{Introduction}

Alpine skiing is a very popular sport worldwide but has a significant risk of injury. Modern preventive procedures enhanced by the emergence of equipment and skis of better quality as well as today's skiing technique, have significantly reduced the total number of injuries [1]. Alpine skis have changed a lot in the last few decades. Carving skis have brought the most changes, such as length, width and sidecut radius [2]. In the early 2000 s, these skis were found to contribute to a greater risk of anterior cruciate ligament injuries, due to the more severe knee injuries being reported since these changes have been introduced [3]. On the other hand, Haaland et al. [1] found a lower rate of injuries in the three seasons after the new ski regulation (the 2012/2013 International Ski Federation Alpine World Cup season) compared with the six seasons before.

In order to develop efficient strategies in preventing these injuries, a comprehensive model of the causes of injuries should be used. Internal and external factors should be considered, such as course setting, weather and snow conditions, skier's technical errors and equipment that contributes most to injuries $[4,5]$.

According to the data of the International Ski Federation Injury Surveillance System, during the winter season every third competitor of the World Ski Cup sustains an injury. The absolute injury rate totals 36.2 injuries per 100 World Cup competitors per ski season, the occurrence is higher for male skiers 39.7 and lower for female skiers 31.9 [6]. Injuries in slalom were found to have increased by 4.9 injuries/1000 runs, giant slalom 9.2 injuries/1000 runs, super-giant slalom 11 injuries/1000 runs, downhill 17.2 injuries/1000 runs. However, when taking into account the number of injuries in relation to time, i.e. hours spent skiing, all disciplines proved to be equally dangerous at the World Cup level [7]. As many as 45\% of all injuries in the World
Cup occurred during official competitions or world championships, while only $25.1 \%$ during training on the snow $[8,9]$. Most commonly, they involve knee injuries, i.e. a complete rupture of the anterior cruciate ligament [8]. The most common moment of injury for competitors is during turns and landing, i.e. immediately after jumps. The most common site of injury is the last quarter of the racetrack (46\%). Contact with the gates during competitions, directly or indirectly, contributes to up to $30 \%$ of injuries. Head and upper body injuries are mostly (96\%) associated with collisions/accidents, while knee injuries $(83 \%)$ occur during skiing or falling [10].

After an injury, athletes often have a fear of re-injury [11], and this fear can be blocking in activities [12], so we are talking about a phobia - an excessive and persistent fear of a situation or object that is not in fact dangerous. Although people often realize that this is not rational, such fear leads to a strong desire to avoid such situations. They may dismiss or ignore their fears when they find themselves in a "safe" place; however, they continue to believe that they are really threatened when faced with what is the object of their fear. Phobias, in comparison to other fears, are not adaptive and incapacitate a person because they interfere with regular activities [13]. Kinesiophobia or a "fear of movement" is a condition in which an individual experiences a fear of physical movement and activity as a result of feeling susceptible to injuries [14] or recurrent injuries [11, 12, 15]. Fear of reinjury, which is very similar to kinesiophobia, could be the main reason for reduction in sport activity [15]. It may prevent a return to sport even when the symptoms and tissue injuries are completely resolved [12], through the generation of postural dysfunction due to the formation of compensatory movement mechanisms that could cause the imbalance of the body and its segments [16] with the potential threat of increased load and strain on structures that have not sustained any injuries [17]. Considering the frequency of injuries among top-level skiers, 
it is reasonable to expect they would have kinesiophobia, even though according to the available literature no research about the appearance of kinesiophobia among this group has been found.

The aim of the research was to examine the level of kinesiophobia in skiers who have sustained knee injuries.

\section{Material and methods}

\section{Subjects}

The research was conducted on a sample consisting of 33 alpine skiers (22 female and 11 male skiers) from Croatia, Slovenia, Serbia and Montenegro. The mean age of the subjects was 24 years, with a standard deviation of 7.391. The subjects have been engaged in competitive skiing for an average of 14.7 years, with $\mathrm{SD}=5.4$, ranging from 6 to 30 years.

\section{Procedure}

The data were collected via the Internet, with prior instructions and explained purpose of the research, using Google tools. The survey was conducted through December 2019 and January 2020, and the data were collected anonymously, meeting the ethical standards. All subjects understood the details of the study procedure since they were notified of the research in a message sent through email or Facebook. All participants gave their informed consent according to the protocol approved by the examiner. The sample was formed using the snowball sampling where a link to the research was sent to several participants who the researchers knew were top skiers that had sustained injuries, and they were asked to pass the link on to other referrals having similar traits.

\section{Instrument}

The part of the instrument compiled for the purposes of this research consists of 12 questions related to sociodemographic data, such as age, gender, and questions regarding skiing (years of experience in skiing, the disciplines they have engaged in or are engaged in and their dominant discipline, the number and type of injuries and knee surgeries they have had and whether they are still actively skiing). Two more questions have been added: health self-assessment ( 1 - poor, 5 - excellent $)$ and comparison of one's health condition with the previous year, where a higher result means a better health condition (1- much worse than a year ago, 5 - much better than a year ago).

The second part of the instrument refers to the Tampa scale for kinesiophobia (TSK) consisting of 17 items [18]. It examines a condition in which a subject has a fear of physical movement or activity as a result of feeling susceptible to injury or recurrent injuries. These are closed-type questions, and the answers offered range from 1 - fully disagree to 4 - fully agree. It is possible to include two subscales on the TSK, specifically activity avoidance and somatic focus, which is called pathological somatic focus in the literature. Activity avoidance is a subscale that contains 8 items, and reflects the belief that increased activity can result in the re-occurrence of injuries or increased pain [19]. Somatic focus is a subscale that includes 5 items, and represents basic severe and medical problems. According to the instructions [20], the four items are recoded so that a higher score always reflects a more pronounced kinesiophobia. The questions describe a condition in which the subject has a fear of physical movement or activity as a result of feeling susceptible to injuries or recurrent injuries, for instance: My body is telling me I have something dangerously wrong, or It's really not safe for a person with a condition like mine to be physically active.

\section{Statistical analysis}

The Shapiro-Wilk test was performed for testing the normality of distributions of subscales and total score of Tampa scale. The Shapiro-Wilk test did not show statistically significant deviations from the normal distribution; $\mathrm{P}$ value for total score was 0.141 , for activity avoidance $\mathrm{P}$ was 0.857 , and for somatic focus 0.618 .

Statistical analysis was performed with the SPSS software, version 23.0 (SPSS Inc., Chicago, IL, USA). The level of statistical significance was set at $\mathrm{p} \leq 0.05$.

\section{Results}

The study was conducted on 33 skiers, of whom $66.7 \%$ were women and $33.3 \%$ were men. The data related to the skiing experience of the subjects and their injuries are shown in Table 1.

Figure 1 shows that $30.3 \%$ of the subjects had only one knee injury and that in $69.7 \%$ of the cases the injury reoccurred.

The injury to the anterior cruciate ligament (ACL) is the most common one, however, with concomitant injuries to the meniscus and other parts of the knee with $36.4 \%$ (posterior cruciate ligament, medial and lateral collateral ligament, and cartilage). Independent ACL injuries are present with $21.2 \%$, while the ACL injury combined with the meniscus is more common with more than $24 \%$. The ACL injury combined with another knee injury makes up only $6.1 \%$, while the meniscus injury combined with another type of injury totals $12.1 \%$. This leads us to a conclusion that most skiers' knee injuries occur due to the rupture of the anterior cruciate ligament and the meniscus.

Out of a total of 33 skiers, 5 engage only in technical disciplines, slalom and giant slalom. Twelve subjects also engage in super-giant slalom in addition to technical disciplines, and 16 skiers (the majority) engage in all disciplines, meaning both the technical and fast ones.

The dominant discipline among the skiers surveyed (Fig. 2) shows that technical disciplines are dominant with a total of $91 \%$.

The results of the TSK are shown in Table 2. The results are ranked from the answer with the lowest mean value, i.e. the question with which the subjects agree the least (this is also the question with the least pronounced kinesiophobia) to those they agree with the most.

Table 1. Skiing experience and injuries of skiers $(n=33)$

\begin{tabular}{|c|c|c|c|c|c|}
\hline & Mean & Median & SD & Min & Max \\
\hline Years of skiing experience & 14.7 & 14 & 5.4 & 6 & 30 \\
\hline Number of knee injuries & 2.45 & 2 & 1.9 & 1 & 11 \\
\hline
\end{tabular}

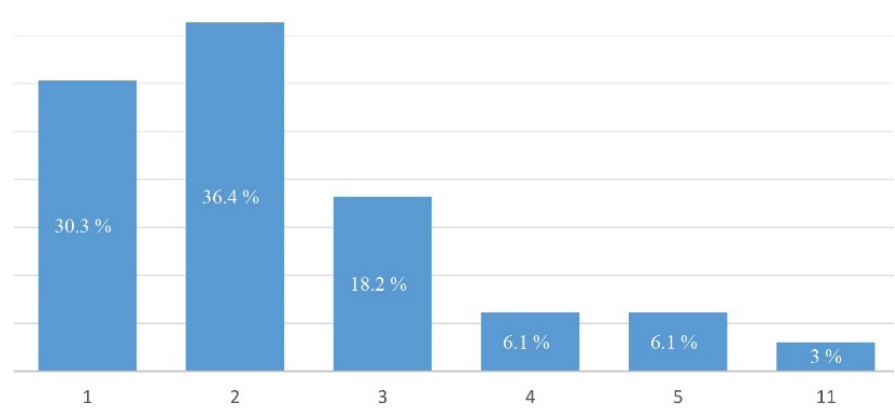

Figure 1. Number of knee injuries in skiers $(\mathrm{n}=33)$ 


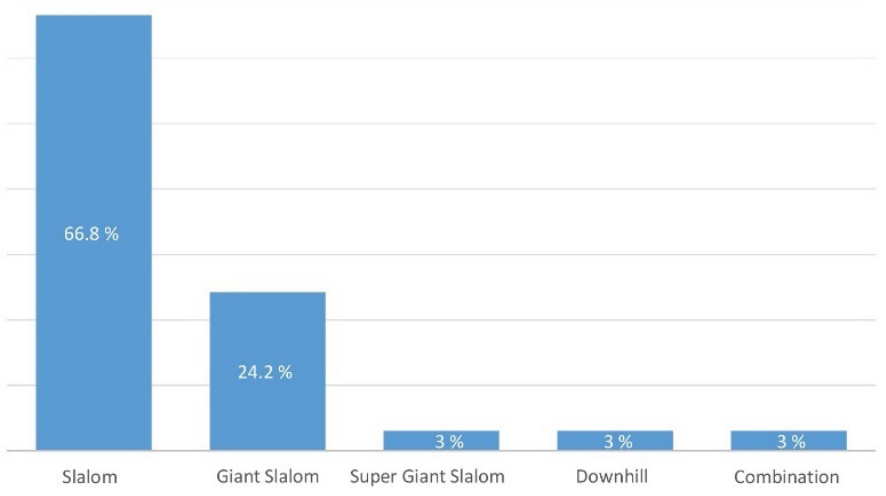

Figure 2. Skiers' dominant discipline $(\mathrm{n}=33)$

Table 2. Descriptive parameters for items of TSK for skiers $(n=33)$

\begin{tabular}{|c|c|c|c|c|}
\hline \multicolumn{2}{|r|}{ Items of Tampa scale for kinesiophobia } & \multirow{2}{*}{$\begin{array}{c}\text { Mode } \\
1\end{array}$} & \multirow{2}{*}{$\begin{array}{l}\text { Mean } \\
1.52\end{array}$} & \multirow{2}{*}{$\begin{array}{r}\text { SD } \\
0.712\end{array}$} \\
\hline 1 & $\begin{array}{l}\text { I can't do all the things normal people do } \\
\text { because it's too easy for me to get injured }\end{array}$ & & & \\
\hline 2 & $\begin{array}{l}\text { It's really not safe for a person with a condi- } \\
\text { tion like mine to be physically active }\end{array}$ & 1 & 1.58 & 0.867 \\
\hline 3 & $\begin{array}{l}\text { If I were to try to overcome it, my pain would } \\
\text { increase }\end{array}$ & 1 & 1.67 & 0.736 \\
\hline 4 & $\begin{array}{l}\text { I'm afraid that I might injury myself if I } \\
\text { exercise }\end{array}$ & 1 & 1.82 & 0.769 \\
\hline 5 & $\begin{array}{c}\text { My body is telling me I have something } \\
\text { dangerously wrong }\end{array}$ & 1 & 1.91 & 0.914 \\
\hline 6 & $\begin{array}{l}\text { I am afraid that I might injure myself acci- } \\
\text { dentally }\end{array}$ & 2 & 1.97 & 0.810 \\
\hline 7 & $\begin{array}{c}\text { My pain would probably be relieved if I were } \\
\text { to exercise }\end{array}$ & 1 & 2.00 & 1.031 \\
\hline 8 & $\begin{array}{l}\text { My accident has put my body at risk for the } \\
\text { rest of my life }\end{array}$ & 1 & 2.03 & 0.984 \\
\hline 9 & $\begin{array}{l}\text { People aren't taking my medical condition } \\
\text { seriously enough }\end{array}$ & 2 & 2.15 & 0.870 \\
\hline 10 & Pain always means I have injured my body & 2 & 2.15 & 0.906 \\
\hline 11 & $\begin{array}{l}\text { I wouldn't have this much pain if there wer- } \\
\text { en't something potentially dangerous going } \\
\text { on in my body }\end{array}$ & 2 & 2.15 & 0.834 \\
\hline 12 & $\begin{array}{l}\text { No one should have to exercise when he/ } \\
\text { she is in pain }\end{array}$ & 2 & 2.15 & 0.870 \\
\hline 13 & $\begin{array}{l}\text { Although my condition is painful, I would be } \\
\text { better off if I were physically active }\end{array}$ & 2 & 2.21 & 0.893 \\
\hline 14 & $\begin{array}{l}\text { Just because something aggravates my pain } \\
\text { does not mean it is dangerous }\end{array}$ & 3 & 2.58 & 0.830 \\
\hline 15 & $\begin{array}{l}\text { Simply being careful that I do not make any } \\
\text { unnecessary movements is the safest thing I } \\
\text { can do to prevent my pain from worsening }\end{array}$ & 3 & 2.70 & 0.918 \\
\hline 16 & $\begin{array}{l}\text { Even though something is causing me a lot } \\
\text { of pain, I don't think it's actually dangerous }\end{array}$ & 3 & 2.70 & 0.883 \\
\hline 17 & $\begin{array}{l}\text { Pain lets me know when to stop exercising } \\
\text { so that I don't injure myself }\end{array}$ & 3 & 2.82 & 0.917 \\
\hline
\end{tabular}

The last three statements in the table are the ones with which the subjects agreed the most on average, in fact the statements with which they express the highest degree of kinesiophobia. The subjects expressed the greatest agreement with the statement Pain lets me know when to stop exercising so that I don't injure myself. The subjects agree generally to strongly with as many as 11 statements. The dominant value of 3 , which is the highest one, was also obtained for the statements at the bottom of the table that reflect the most pronounced kinesiophobia. The items under ordinal numbers 14 and 16 are recoded, thus a higher score demonstrates greater disagreement with them.

Results on the subscales (Tab. 3) are a little better than results of the overall kinesiophobia. In the subscale "Activity Avoidance" the mean value totals 16.21, and in the subscale "Somatic Focus" the mean value totals 10.39. The average on the kinesiophobia questionnaire is 36 points, which is close to the critical threshold of 37 points [21]. The range is from 28 to 49, and the most common overall score is 36 (15.2\%), followed by a score of 38 with $9.1 \%$. It is also evident that as many as $36 \%$ of subjects have a high level of kinesiophobia since their overall score on the TSK totals 37 points or higher.

The last two questions were related to health self-assessment. The majority of the sample mostly assess their health as satisfying or poor (Fig. 3). Their health is mostly approximately the same or a little worse than a year ago (Fig. 4).

Table 3. Descriptive statistics for the subscales and the total result of the TSK $(\mathrm{n}=33)$

\begin{tabular}{|c|c|c|c|c|c|}
\hline & Mean & SD & Min & Max & $\begin{array}{c}\text { Scale } \\
\text { range }\end{array}$ \\
\hline Activity Avoidance & 16.21 & 3.343 & 8 & 23 & $8-32$ \\
\hline Somatic Focus & 10.39 & 2.715 & 5 & 16 & $5-20$ \\
\hline Kinesiophobia total & 36.09 & 5.491 & 28 & 49 & $17-68$ \\
\hline
\end{tabular}

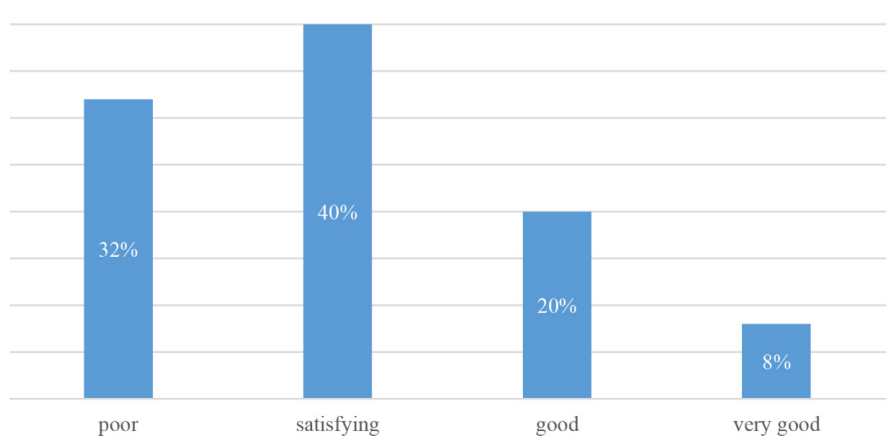

Figure 3. Health self-assessment $(\mathrm{n}=33)$

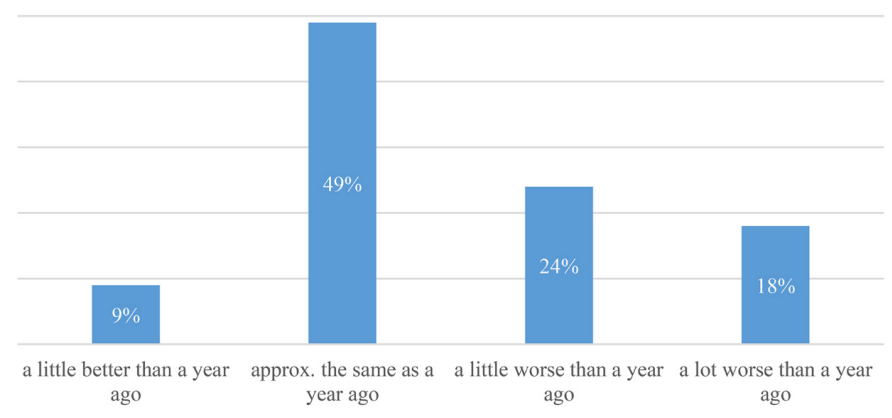

Figure 4. Health comparison $(\mathrm{n}=33)$ 
We were also interested in comparisons in the level of kinesiophobia with regard to certain socio-demographic traits, i.e. traits related to sports and injuries. The results of the comparison with respect to gender showed that the only two significant differences were obtained for the item I am afraid that I might injure myself accidentally $(\mathrm{t}=2.262 ; \mathrm{p}=0.031$; Cohen's $\mathrm{d}=0.82)$, where women scored significantly higher $(\mathrm{MF}=2.18$ with $\mathrm{SD}=0.853 ; \mathrm{MM}=1.55$ with $\mathrm{SD}=0.522$ ), and for the item Simply being careful that I do not make any unnecessary movements is the safest thing I can do to prevent my pain from worsening $(\mathrm{t}=2.451 ; \mathrm{p}=0.020 ; \mathrm{d}=0.90)$, where again women had a significantly higher average score $(\mathrm{MF}=2.95$ with $\mathrm{SD}=0.785$; $\mathrm{MM}=2.18$ with $\mathrm{SD}=0.982$ ). Therefore, women express a significantly greater fear that they might be accidentally injured, and that they must be careful and avoid unnecessary movements to prevent the pain from aggravating. In both cases $\mathrm{d}$ is higher than 0.8 , so we can talk about large effect size [22]. Based on skiing experience, number of knee injuries, number of surgeries, general level of kinesiophobia, scores on the subscales, remaining items, as well as health self-assessment, no significant difference was obtained between female and male skiers. In the overall result, as on both subscales, women achieved a higher score; however, these differences, as already mentioned, are not significant.

With regard to whether skiers have injured only one or both knees, no significant difference was found. With regard to whether skiers have had only one knee surgery so far (12 skiers), or two or more of them (21 skiers), the t-test shows three statistically significant differences. The first one regards the number of knee injuries $(t=2.320 ; p=0.027 ; d=0.84)$. As expected, skiers who have had two or more knee surgeries also have significantly higher number of knee injuries ( 3 on average) than those who have had only one surgery (1.5 injuries). The difference is also significant regarding the item: If I were to try to overcome it, my pain would increase $(\mathrm{t}=2.065 ; \mathrm{p}=0.047 ; \mathrm{d}=0.76)$. Average result for skiers with one knee surgery is $M=1.33$ with $\mathrm{SD}=0.492$; and for those with more surgeries $\mathrm{M}=1.86$ with $\mathrm{SD}=0.793$. For the item My body is telling me I have something dangerously wrong, skiers with one surgery had $\mathrm{M}=1.50$ with SD 0.522 , and those who had more than one $\mathrm{M}=2.14$ with SD $1.014(\mathrm{t}=2.401$; $\mathrm{p}=0.023$; $\mathrm{d}=0.73)$. Skiers who have had two or more knee surgeries express a significantly higher degree of kinesiophobia on mentioned items. Size effects are between 0.73 and 0.84 , so they can be considered large.

By applying a simple ANOVA, we compared the subjects who have only injured the anterior cruciate ligament $(n=7)$, with those who had a combination of two types of injuries ( $\mathrm{n}=$ 14), and those who had a combination of three types of injuries $(\mathrm{n}=12)$; however, no difference proved to be statistically significant.

The relationship between the variables was verified using the Pearson's and Spearman's correlation coefficient, respectively, for variables that are extremely asymmetric (age, skiing experience, number of knee injuries and number of surgeries). The overall score on the TSK is positively and moderately related to the number of knee injuries, the risk level slightly exceeds the significant threshold of 5\% $(\rho=0.337 ; p=0.055)$, and to the health comparison compared to a year ago $(r=0.361 ; p=0.039)$ : the more knee injuries the subject has had, and the more positive the health assessment is, the higher the kinesiophobia. The link between kinesiophobia and age is also significant, moderate and negative $(\rho=-0.441 ; p=0.018)$ : the older the subjects, the lower the kinesiophobia. Age was also significantly associated with activity avoidance $(\rho=-0.440 ; p=0.010)$, as was the num- ber of knee injuries with somatic focus $(\rho=0.403 ; p=0.020)$ : the older the subjects, the less they avoid activity, and the more knee injuries they have had, the more pronounced their somatic focus is.

\section{Discussion}

This research is about relatively young skiers with an average of 24 years of age, but with extensive skiing experience: on average, they have been "on the snow" for 14.7 years. It is therefore not surprising that they have had knee injuries, and that more than two-thirds of the sample have had recurrent knee injuries. We did not ask the subjects about other possible injuries resulting from skiing, rather we asked solely about knee injuries. Therefore, it is safe to assume that the overall situation involving injuries is even more unfavorable. However, as skiers most often sustain knee injuries [7, 8], that was our focus. Knee injuries in professional skiers account for $39 \%$ of all injuries, and in severe injuries up to $60 \%$ [23]. The most common knee injury our subjects have sustained is ACL rupture, which is consistent with the literature $[8,24]$.

The incidence of injuries with regard to gender is not unequivocal. Thus, Westin et al. [25] state that no link between gender and the occurrence of injuries has been proven, while Flørenes et al. [8] state that a higher incidence of injuries has been recorded in male competitors but female skiers suffer twice as many severe knee injuries as male skiers. In our study, women make up as much as $66.7 \%$ and all of them have suffered knee injuries. Therefore, it is not safe to say that women are "spared" from knee injuries. Made [26] emphasizes a wider pelvis and weaker muscles as the main reasons for the increased number of injuries in women, which can affect greater knee valgus, which would make the ACL prone to injuries.

What interested us most in this research was the level of kinesiophobia in skiers who had had at least one knee injury at the time of the research. The average overall score of the surveyed skiers who have sustained knee injuries on the TSK totals 36 , which is just below the critical threshold of 37 points, which already represents the existence of kinesiophobia as a problem that needs to be attended to. It is precisely the development of an unconscious or conscious fear of recurrent injuries, i.e. kinesiophobia that can result in recurrent injuries or poorer athlete performance.

Our study showed a high level of kinesiophobia in as many as $36 \%$ of the surveyed skiers. The scores obtained on the subscales are slightly better than the total kinesiophobia since the items with critical scores have obviously not been included in their calculation. If we relativize the overall scores in order to facilitate comparison and divide them by the corresponding number of items, it becomes evident that the lowest average can be found on the Activity Avoidance subscale - 2.03, followed by Somatic Focus 2.08, and the highest for total kinesiophobia-2.12. The three items with which the subjects expressed the greatest agreement relate to the need to be careful in order to prevent the aggravation of pain, recognising that the intense cause of pain indicates danger to the body, and that pain is a signal telling them when they need to stop exercising to avoid injuries. Apparently, the subjects adopted increased caution and listen to their own bodies in order to be able to determine during an activity where the limit they must not cross lies if they do not want to further harm their body. This is significantly different from the common attitude of "no pain, no gain" in sports [27].

Gender comparisons have shown that women demonstrate significantly greater concern when it comes to being cautious 
during movements. With regard to whether skiers have injured only one or both knees, the type of injury involved, whether the subjects are still actively skiing or not, no statistically significant differences have been found for individual TSK items, as well as for the overall level of kinesiophobia. It is safe to assume that even one injury in itself, regardless of its type, causes kinesiophobia. There does not appear to be a cumulative effect of multiple injuries. Although it is true that the link between kinesiophobia and the number of knee injuries is not significant, it is very close to the significance threshold ( $p=0.055)$. It is possible that a skier's experience of having successfully overcome a previous injury and having returned to the snow gives the skier confidence that he will successfully overcome the situation with a repeated injury, and this prevents him from having great fear of an injury of a second or higher order. It seems that more attention should be paid to examining this link in the future.

The number of surgeries shows a certain effect. Therefore, skiers who have had two or more knee surgeries so far show significantly greater agreement with the statements If I were to try to overcome it, my pain would increase, and the statement My body is telling me I have something dangerously wrong compared to skiers who have undergone just one surgery. The fact that there was a surgery indicates that it was a severe injury and that the recovery was longer and more demanding, which causes more pronounced consequences in the emotional life of a skier, fear in particular.

The examination of correlations shows that the more positive the health comparison is compared to a year ago, the higher the kinesiophobia. This finding is unexpected, but perhaps it can be explained as follows: kinesiophobia may still be present even when a skier has fully physically recovered from an injury. It would be very helpful to ask subjects how long it has been since the last injury and surgery in order to gain insight into whether kinesiophobia is a short-term or long-term consequence of an injury. Age proved to be a significant correlate: the older the subjects, the lower the kinesiophobia, and the less pronounced the activity avoidance. We can assume that young skiers experience their first injuries the most dramatically and react with the greatest amount of fear, and after undergoing rehabilitation and recovery one or more times, the fear becomes less pronounced since they are already acquainted with the whole recovery process and they have already experienced return to skiing despite injuries. On the other hand, the more knee injuries the subjects have had, the more pronounced their somatic focus is. This finding is expected since through injuries and rehabilitation, skiers have really learned how to be focused on reading signals from the injured area, and they have become and remained sensitive to even the smallest changes that occur within these structures.

Today, the goal of every professional athlete is not only to participate, but to win as well. Unfortunately, the results come first, which is why strains and burdens come before the athlete and his health. That is precisely why the number of injuries has been growing and the rehabilitation of athletes plays an important role in order to return to the track as soon as possible. Rehabilitation should be extensive and carried out well so that it does not reoccur. Following the rehabilitation, when athletes are physically ready to return to their sports activities, they should also be provided with several sessions with a psychologist, who would discuss with them any fears and phobias that may have arisen after the injury. With their knowledge, skills, physical and mental preparation, skiers can influence the risk factors contributing to the occurrence of injuries and thus prevent or mitigate them.
The safety of skiers has improved by developing and improving the quality of equipment, improved conditions on ski slopes, appropriate individual training and preparation for demanding and vulnerable situations [10]. Planning and programming annual, monthly and weekly training cycles is one of the most important components in injury prevention. In practice, the situation is that many athletes train in excessive volumes, intensities and frequency and have a fairly large number of competitions over short periods of time as well as on an annual basis without adequate rest. Therefore, excessive fatigue and overtraining are often the causes of injuries in competitors. One of the factors of ski injuries relates to the skiing experience. According to Koehle et al., younger skiers are more prone to injuries [28]. Our results indicate that older skiers have significantly less fear of recurrent injuries.

It is by detecting kinesiophobia before returning to the course that a psychologist, physiotherapist, physician or coach can prevent possible reoccurrence of injuries in athletes. In our research, 36\% of the subjects are experiencing high kinesiophobia; therefore, it is very important that every athlete, in addition to regaining their physical strength, also regain their psychological stability so that they can return to their old habits in an even better condition than before.

Our research possesses certain limitations, and this primarily relates to the size of the sample that prevents broader generalization. Despite the small sample, the research included the majority of competitive skiers from Croatia and the surrounding countries in the region. In addition, it would be interesting to expand the scope of the research and collect data on other injuries and difficulties in skiing, as well as on the time period elapsed since the last injury.

\section{Conclusions}

Our conclusion, based on the obtained results, is that the number of knee injuries in skiing is high and should be influenced through prevention, and as part of their rehabilitation athletes need to be provided with psychological support as well in order to prevent or reduce kinesiophobia and thus prevent recurrent or new injuries.

As the most important conclusion of this research, we would like to point out that almost one third of skiers that have sustained knee injuries experience a critical level of kinesiophobia, and that requires intervention.

\section{References}

1. Haaland B., Steenstrup S.E., Bere T., Bahr R., Nordsletten L. (2016). Injury rate and injury patterns in FIS World Cup Alpine skiing (2006-2015): have the new ski regulations made an impact? British Journal of Sports Medicine 50(1), 32-36. DOI: 10.1136/bjsports-2015-095467

2. Müller E., Schwameder H. (2003). Biomechanical aspects of new techniques in alpine skiing and ski-jumping. Journal of Sports Sciences 21(9), 679-692. DOI: 10.1080/0264041031000140284

3. Johnson R.J., Ettlinger C.F., Shealy J.E. (2008). Update on injury trends in alpine skiing. Journal of ASTM International 5(10), 1-12. DOI: 10.1520/JAI102046

4. Bahr R., Krosshaug T. (2005). Understanding injury mechanisms: a key component of preventing injuries in sport. British Journal of Sports Medicine 39(6), 324-329. DOI: 10.1136/bjsm.2005.018341 
5. Bere T., Flørenes T.W., Krosshaug T., Nordsletten L., Bahr R. (2011). Events leading to anterior cruciate ligament injury in World Cup Alpine Skiing: a systematic video analysis of 20 cases. British Journal of Sports Medicine 45(16), 1294-1302. DOI: 10.1136/bjsports-2011-090517

6. Bere T., Flørenes T.W., Nordsletten L., Bahr R. (2014). Sex differences in the risk of injury in World Cup alpine skiers: a 6-year cohort study. British Journal of Sports Medicine 48(1), 36-40. DOI: 10.1136/bjsports-2013-092206

7. Spörri J., Kröll J., Gilgien M., Müller E. (2017). How to prevent injuries in alpine ski racing: What do we know and where do we go from here? Sports Medicine 47(4), 599-614. DOI: 10.1007/s40279-016-0601-2

8. Flørenes T.W., Bere T., Nordsletten L., Heir S., Bahr R. (2009). Injuries among male and female World Cup alpine skiers. British Journal of Sports Medicine 43(13), 973-978. DOI: 10.1136/bjsm.2009.068759

9. Flørenes T.W., Nordsletten L., Heir S., Bahr R. (2012). Injuries among World Cup ski and snowboard athletes. Scandinavian Journal of Medicine E Science in Sports 22(1), 58-66. DOI: 10.1111/j.1600-0838.2010.01147.x

10. Bere T. (2013) Mechanisms of injuries in World Cup alpine skiing. Doctoral dissertation, Norwegian school of sports sciences, Oslo.

11. Flanigan D.C., Everhart J.S., Pedroza A., Smith T., Kaeding C.C. (2013). Fear of reinjury (kinesiophobia) and persistent knee symptoms are common factors for lack of return to sport after anterior cruciate ligament reconstruction. Arthroscopy 29(8), 1322-1329. DOI: 10.1016/j.arthro.2013.05.015

12. Hsu C.J., Meierbachtol A., George S.Z., Chmielewski T.L. (2017). Fear of reinjury in athletes. Sports Health 9(2), 162167. DOI: $10.1177 / 1941738116666813$

13. Hawton K.E., Salkovskis P.M., Kirk J.E., Clark D.M. (1989). Cognitive behaviour therapy for psychiatric problems: A practical guide. Oxford: University Press.

14. Knapik A., Saulicz E., Gnat R. (2011). Kinesiophobia - introducing a new diagnostic tool. Journal of Human Kinetics 28, 25-31. DOI: 10.2478/v10078-011-0019-8

15. Ardern C.L., Webster K.E., Taylor N.F., Feller J.A. (2011). Return to sport following anterior cruciate ligament reconstruction surgery: a systematic review and meta-analysis of the state of play. British Journal of Sports Medicine 45(7), 596-606. DOI: 10.1136/bjsm.2010.076364

16. Myers T.W. (2014). Anatomy trains e-book: Myofascial meridians for manual therapists and movement professionals. Edinburgh: Churchill Livingstone.

17. Noehren B., Kline P., Ireland M.L., Johnson D.L. (2017). Kinesiophobia is strongly associated with altered loading after an ACL reconstruction: implications for re-injury risk. Orthopaedic Journal of Sports Medicine 5(7), (suppl 6). DOI: $10.1177 / 2325967117$ S00323

18. Miller R., Kori S., Todd D. (1991). The Tampa Scale for Kinesiophobia. Tampa, FL: Better World. Retrieved April 20, 2020, from https://betterworldhealthcare.com/tampa-scale-of-kinesiophobia-tsk/

19. Tkachuk G.A., Harris C.A. (2012). Psychometric properties of the Tampa Scale for Kinesiophobia-11 (TSK-11). The Journal of Pain 13(10), 970-977. DOI:10.1016/j.jpain.2012.07.001

20. Goubert L., Crombez G., Van Damme S., Vlaeyen J.W., Bijttebier P., Roelofs J. (2004). Confirmatory factor analysis of the Tampa Scale for Kinesiophobia: invariant two-factor model across low back pain patients and fibromyalgia patients. The Clinical Journal of Pain 20(2), 103-110. DOI: 10.1097/00002508-200403000-00007
21. Bränström H., Fahlström M. (2008). Kinesiophobia in patients with chronic musculoskeletal pain: differences between men and women. Journal of Rehabilitation Medicine 40(5), 375-380. DOI: 10.2340/16501977-0186

22. Kolesarić V., Tomašić Humer J. (2016). Veličina učinka. Osijek: Filozofski fakultet Sveučilišta Josipa Jurja Strossmayera u Osijeku. [in Croatian]

23. Mayr H.O., Chèze L. (2015). The knee injuries in skiing: Mechanisms and assessment. In F. Colloud, M. Domalain, T. Monnet (eds.) Applied Program - Sports Related Injuries and Prevention (pp. 1357-1360), Poitiers, France.

24. Kim S., Endres N.K., Johnson R.J., Ettlinger C.F., Shealy, J.E. (2012). Snowboarding injuries: trends over time and comparisons with alpine skiing injuries. American Journal of Sports Medicine 40(4), 770-776. DOI: 10.1177/0363546511433279.

25. Westin M., Alricsson M., Werner S. (2012). Injury profile of competitive alpine skiers: a five-year cohort study. Knee Surgery, Sports Traumatology, Arthroscopy 20(6), 1175-1181. DOI: $10.1007 / \mathrm{s} 00167-012-1921-x$

26. Made C. (2009). Alpine ski sport injuries in Swedish Lapland. Doctoral dissertation, Umeå University.

27. Wiese-Bjornstal D.M., Smith A.M., Shaffer S.M., Morrey M.A. (1998). An integrated model of response to sport injury: Psychological and sociological dynamics. Journal of Applied Sport Psychology 10(1), 46-69. DOI: 10.1080/10413209808406377

28. Koehle M.S., Lloyd-Smith R., Taunton J.E. (2002). Alpine ski injuries and their prevention. Sports Medicine 32(12), 785-793. DOI: 10.2165/00007256-200232120-00003

Submitted: March 25, 2021

Accepted: April 9, 2021 